means give to these institutions a dominant voice in its government. But should, as the commissioners evidently prefer, no new university be founded, but the existing University of London be so modified in its constitution as to make it a teaching university for the metropolis, whilst it admits to its examinations and degrees all qualified students, wherever they may be educated, then both the provincial Colleges and the present graduates will have to be heard. The provincial Colleges may reasonably claim that in adjusting the details for the government and administration they should have a voice in questions connected with the arrangement of the curricula of study, the scope and method of examination, and the appointment of examiners, in all of which they would have as direct an interest as the metropolitan Colleges themselves. The existing graduates should insist that the standard of examination should be efficient, and that the cry which one sometimes hears of degrees on "easy" terms for London students should not be listened to. But if the reasonable requests of the provincial Colleges be not met in an equitable manner, it will be for them to reconsider their position. If I read the Charter of the Victoria University aright, the Colleges which it has the power to receive into the federation are not restricted to such as are situated in the north of England, but may be localised anywhere in England and Wales, the essential conditions being that they have an efficient staff of teachers, and that the means and appliances for teaching are on a sound basis. The Charter therefore is so wide that Birmingham and other great cities may, if they think fit, claim to have their Colleges admitted members of the federation under the central authority of the Victoria University when they are able to fulfil the conditions imposed by the Charter of that University.

But it is possible that Birmingham may have a higher ambition. It regards itself as the capital of the Midlands, and has good grounds for assuming this honourable distinction. It is a great industrial metropolis. Although the intellectual activity of the district has in many cases taken a political direction, yet since the middle of the last century, when Priestley lived here, Warwickshire and Staffordshire have been the home of many men of light and learning. As the history of Queen's College teaches, much practical sympathy has been shown to the cause of professional education, and the foundation of Mason College proves that your great manufacturers are willing to give freely of their wealth to promote the higher education in literature and science. Birmingham therefore fulfils in many respects the conditions which should precede the granting of a Royal Charter for the conferring of university degrees and privileges. But much more would have to be done before a university worthy of the Midlands could be established on a proper basis. So far as I can judge from a perusal of the calendars of your Colleges there is no provision for the teaching of history, of mental or moral philosophy, and of economics; all of which subjects are powerful instruments in the development of the human mind, and without which a faculty of arts cannot advance much beyond the standard of a high school. Your faculty of science is much more complete, but even hcre there are gaps which would need filling. There is no trace of a faculty of law; but that of medicine, as I have already stated, is organised on a satisfactory basis. It is possible also that there may be other difficulties and hindrances of a local nature which might have to be removed.

What is, however, needed to put your educational institutions into the highest state of efficiency, as was so powerfully and eloquently urged yesterday by Dr. Dale at the opening of the Mason College, is more money. Money is the sinews of education as well as of war. The higher education is an expensive luxury. By a large outlay your educational institutions have become what they now are; and by a further expenditure all the deficiencies to which $I$ have just adverted may be supplied. Competent teachers can always be got if the public will properly pay them, and the materials required for extending your buildings and giving them a proper equipment follow the usual laws of supply and demand. When I tell you that the people of Edinburgh and the district raised, not many years ago, by public subscription $£ 160,000$ for the building and equipment of a new school for the teaching of medicine in the University in that city, I show you what can be done when people are satisfied that a necessity has arisen and that funds must be provided. I cannot therefore but think that if Birmingham and the populous district which surrounds it, abounding in resources and in public-spirited citizens, wish for a university to be established in their midst, the money necessary for the purpose will be forthcoming. Two great requisites are needed for carrying out any great scheme of improvement, either in education o: any other form of human enterpriseviz., faith and courage: faith in the goodness of the cause, and courage to make your belief known and to press it on the attention of the public.

We read that Matthew Boulton, when be founded his great manufactory at Soho, in the middle of the last century, aimed at establishing a character for the excel. lence of his productions. They were to be, says Mr. Smiles "not only honest in workmansbip but tasteful in design." The citizens of the present day will in their educational work, I feel sure, not wish to fall hehind Boulton's ideal. The instruction to be imparted in their colleges they will desire to have sound and thorough, not scamped or dressed up with a little varnish or thin veneer, but honest and true, and with a grace and polish superadded which ean only be imparted by a literary training and culture. Students would then be attracted to Birmingham for the same reason that brought James Watt here more than a hundred years ago, because they would have at command a staff of skilled workmen, and could feel confident that they could rely on the quality of the workmanship.

The multiplication of universities in a country to ar extent sufficient to satisfy the requirements of the people develops in the districts in which they are situated a desire for learning, it improves the intellectual tone of the locality, and encourages the aspiration for something higher than material welfare. But further, in matters strictly educa tional, it preserves the touch between education and examination, which, from the point of view of one's own profession, is of the utmost importance. It is not so many years ago that the medical profession in many parts of England raised for itself a fetish which was called the oneportal system, a method of admission to the privileges of practice which, had it ever come into operation, would have widened the breach between teaching and examination to an extent nuch greater than now prevails. It would, believe, have discouraged healthy and legitimate study, and would have encouraged a wholesale system of cramming. Fortunately for the future of our profession the cry for a single examining board, either for the whole kingdom or for each division of the kingdom, has practically ceased. We may date its cessation from the passing of the Medical Act of 1886, when increased statutory powers were given to the General Medical Council for the inspection of examina. tions, and when the medical profession was empowered by a direct vote to elect representatives on the Council. Should a university in the course of time be established in the Midlands, with Birmingham as its centre, one may be: confident that the examinations in medicine which it would conduct would fulfil all the conditions which the Medical Council might demand, and that the educational stamp imposed upon its graduates would rank as high in the intellectual world as do the most perfeet products of its manufactories amongst the industries of the British Empire.

\section{TREATMENT OF COMPLETE PROLAPSE OF THE RECTUM.}

By HARRISON CRIPPS, F.R.C.S., ASSISTANT SURGEON TO ST. BARTHOLOMEW'S HOSPITAL.

Prolapse of the rectum is the descent of a portion of bowel in a healthy state, and must not be confused with hæmorrhoids, which are chiefly due to a morbid condition of the terminal vessels. The prolapsing portion of bowel may in time become thickened and ulcerated, but this is merely a secondary result. Prolapse may be divided into two varieties-the partial and the complete. In the former the mucous membrane is alone extruded, gliding away from the muscular coat by the stretching of the loose fibrous tissue connecting the two. The complete prolapse is the turning inside out of the lower part of the bowel involving all the coats. Partial prolapse is necessarily of a limited extent, seldom involving more than an inch or two of the membrane. In the complete variety the extent is unlimited, and not 
infrequently a hernial pouch is formed into which small intestine may descend. It is not proposed in this communication to consider the treatment of the common partial prolapse, for this can be easily cured by appropriate operative measures, but rather to discuss the rarer but more serious condition of complete eversion of the bowel. Complete prodapse may occur at any time of life from infancy to old age. It is generally the result of undue straining, though occasionally caused by a polypoid growth. In children, in addition to straining, the disorder is of ten coincident with some weakening illness, causing absorption of the fat in the ischio-rectal fossæ, together with the relaxation of the muscular fibres of the part. Stone in the bladder and phimosis are not infrequently causes of prolapse in children, while occasionally in advanced life it is secondary to chronic constipation, stricture, enlarged prostate, or displaced uterus, any of which may produce injurious straining efforts. A prolapse may occur suddenly, but more frequently it is of a slow formation, slight at first, and gradually increasing. According to my observation, I should say that it is generally a sudden Cormation in children, but a gradual one in advanced life ; accasionally, however, an extensive prolapse may suddenly occur in adults. As an example of this I have recorded a case occurring in St. Bartholomew's Hospital, where a protrusion the size of a child's head appeared suddenly at stool in a woman who had been previously perfectly healthy.

The mechanism of prolapse requires some consideration, sor it is upon the knowledge of this that successtul treatment is founded. It seems probable that the starting-point of complete prolapse arises in the first instance from the wliding of the mucous on the muscular coat, for it is an andoubted fact that if the two coats can be made firmly adherent the prolapse is generally cured. The first effect of this sliding would be to produce a reduplicated fold of mucous membrane, and that such a fold is formed can be readily ascertained by a digital examination. If the patient be told to strain down loose folds of mucous membrane can be felt crowding down on to the finger, and such folds will Grst protrude from the anus, but are quickly followed if the straining effort is continued by complete eversion of the gut.

The evidence that is occasionally afforded by a polypus of the mucous membrane is in the same direction, and shows how an intussusception of all the coats can be produced by a loosening of the mucous membrane at a particular point, for polypi almost invariably cause a reduplication of the mucous membrane at the point of their attachment. It would seem as if the mucous membrane is so loosely attached to the muscular coat as to slip away from it, forming a reduplicated fold, that the bowel will not only be dragged upon by the pressing downwards of the fold, but at this part the gut will be thinned and weakened by the loss of support which a firm mucous membrane would naturally have afforded, and thus a starting-point will be made for a general invagination. As an analogous illustration the finger of a glove may be caken, where, if an invagination is produced, it will start opposite one of the creases where the leather has become thinned. The symptoms produced by complete prolapse vary considerably. In some cases very little trouble is produced, while in others the greatest distress is caused. in many cases, after awhile, complete incontinence of faces will result. In others the prolapsing gut is liable to alceration, with all its concomitant symptoms of discharge and diarrhca, while in every case the patient is subject to the danger of the prolapse becoming suddenly strangulated and irreducible.

Treatment.-This is best considered, first, as regards the method of returning the prolapsed and strangulated bowel in an acute case; and, secondly, as to the means of cure in chronic cases. As a rule, there is not much difficulty in seducing a prolapsed bowel, which can be accomplished by covering the protruding part with vaseline and gently pressing upon it with the tips of the fingers of both hands. It sometimes happens that it cannot be reduced on these easy terms, for, owing to the contraction of the sphincter, the protrusion has become greatly swollen. All manipulation in these cases should be very gentle, for fatal consequences have followed violence in replacing the intestine. Cruveilhier and Roche each mention such a fatality. In Roche's case, whilst the reduction was being attempted the patient made a violent straining effort, causing the rectal wall suddenly to split, and through the rent the whole of the large and a considerable part of the small intestine were extruded, the patient dying in a few hours. If the pro. crusion be strangulated, the patient should be placed under an anresthetic and the sphincter gently stretched. In one case in which I had considerable difficulty in replacing the bowel I found the following manipulation useful. A strip of lint was wrapped round the index finger the point of which was placed in the protruded canal of the gut, which was gently pressed upwards. The piece of lint being dry stuck to the mucous surface, enabling it to be carried up with the finger. The finger, which had previously been oiled, was then with. drawn from inside the lint, which was temporarily left within the bowl. It is not, however, with these acute cases that the surgeon generally has to deal ; for he is far more frequently consulted as to the best method of treating chronic cases. While here, again, the degree of the prolapse, the trouble it occasions, and the age of the patient must be taken into consideration. The treatment may be palliative or operative.

Palliative treatment.-This is often very successful in children. Attention should first be directed as to whether there is any condition present, such as phimosis or stone, causing undue straining; or whether the rectum is the seat of any polypoid growth. Assuming none of these are present, the ground is cleared for rational treatment. If the child is thin, plenty of good food, milk, and cod-liver oil, will help to restore the cushion of fat in the ischio-rectal fossæ, the absence of which doubtless facilitates the descent of the bowel. If in children prolapse can be prevented for two or three months, it will generally happen that the cure is effected by natural means-presumably by the attachments of the gut having time to become shortened, and consolidated. To obtain this desirable result, great care must be taken to prevent the motions becoming constipated. This can be generally attained by cod-liver oil and diet, while the position in which the child passes its motions is a most essential point. It must on no account be allowed to sit up to do so. The motion must be passed as the child lies on its side on the edge of the bed. If, while in this position, at the moment the motion is passing the mother or nurse will draw one of the buttocks upwards so as to pull the anus a little out of the middle line, it will almost certainly prevent the prolapse from coming down. After the motion the child should be kept lying on its side for sone minutes, when a pad and a $T$-bandage should be firmly applied. This need not be worn for more than an hour or two. If the foregoing measures are adopted, operative measures rarely become necessary in children.

Palliative treatment in the adult is much less satisfactory than in children, and seldom succeeds in effecting a cure. Nevertheless, it may be right to give it a trial before adopting other means. The treatment which, with some slight modification, was long ago advocated by Brodie may be tried, but benefit cannot be expected unless it is pursued for some months. The patient should be cautioned against all straining, and should turn over on the side as far as practicable whilst passing a motion. A small injection of eight ounces of warm water should be given before going to the closet, while after the motion is passed one ounce of quite cold water may be injected and retained, acting as a local muscular stimulant. If there be any superficial ulceration on the prolapsing bowel, a drachm of tincture of catechu may be added to the cold water.

Operative treatment.-Many cutting operations have been devised, varying from the removal of small portions up to the complete excision of the entire mass. Speaking generally, the partial removals have not been efficient. The most recent advocate of complete excision is Mr. Frederick Treves, and any opinion expressed as to its value by this eminent surgeon demands respectful consideration. $\mathbf{M r}$. Treves, as is well known, is no advocate for specialism in surgery, but those of his professional brethren who have devoted some attention to the part under consideration naturally look critically upon a procedure involving removal of the entire organ. That complete excision may occasionally be the only method of effectually dealing with a severe case is possible, but before advising such a procedure two points have to be considered : the one, the risk involved in the operation; the other, the probability of effecting a cure without producing a stricture It requires but slight insight into the principles of surgery to know that six or eight inches of prolapse involving the opening of the peritoneal pouch, probably containing small intestine, cannot be removed without an appreciable risk to the life of the patient. As to the chance of a stricture following the operation, there is not sufficient evidence at present on which to form a reliable opinion, but that it may 
occasionally do so is certain. Of course it is not asserted that either the risk to life or the chance of a stricture prohibits excision for the relief of so distressing a condition as is produced by an extensive prolapse; nevertheless it makes it incumbent to defer the operation until remedies of a less severe nature have proved a failure. In the lincar cautery we have an alternative operation, founded upon sound physiological principles, and one in which the risk is inappreciable, while the result is generally most satisfactory if sufficient care is taken in the subsequent treatment. If the rationale of this method is to be properly understood, it must be remembered what has already been said with reference to the mechanism of prolapse, and how it appears to be primanily produced by the slipping of one coat on the other, tonether with a want of sufficient rigidity in the walls to prevent invagination. The indication for treatment is to find some plan binding the muscular and mucous coats together, so as to prevent this initial slipping, while at the same time, if a certain amount of thickening can be produced so as to give a little extra stiffness to all the coats of the bowel, invagination becomes mechanically more difficult. The necessary conditions can be fulfilled by exciting inflammation in the submucous tissue. The exudation thus produced cements the two coats more tirmly together, preventing sliding, while at the same time it affords an increased stiffness to the whole bowel. The actual cautery, as advised by Van Buren, is an admirable means of exciting the necessary inflammation. The method of operating is as follows: The bowels having been thoronghly cleared ont, the patient, being under an anæesthetic, is placed. in the lithotomy position. With a little manipulation the prolapse can be generally made to protrude. Four lines of cautery are now drawn along the bowel in its long axis, one in front, one behind, and one on either side. It should be managed so that these lines commence well within the canal of the bowel at the apex of the protrusion, and terminate at the anal margin. The width of the lines should be about a quarter of an inch, and their depth such as thorougbly to sear but not actually to destroy the inucons membrane. The lines of the cautery are pretty sure to cross one or more large dilated veins. These should be tied on $\epsilon$ ither side of the lines, a needle threaded with silk being passed beneath them. The whole operation should be done pretty quickly, and the bowel returned, otberwise congestion and swelling will make its reduction difficult. If the prolapse does not protrude at the time of the operation, the lines of cautery can be drawn along the bowel in situ by using a full-sized duckbill speculum, shifted as required for each line. Paquelin's cautery is not suitable for the purpose, for it is too hot when first applied and cools too rapidly. The instrument I employ is similar to that shown in the diagram. It is comparatively short in length,

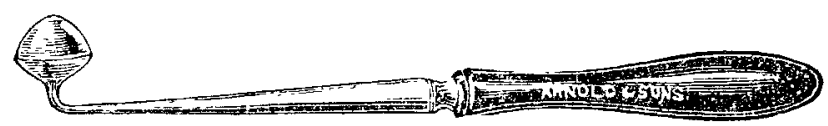

so as to admit of easy manipulation, and is made with a conical head, half an inch in diameter, bent at right angles. The shaft at the bend is made thin so as to prevent the heat bein $\mathrm{g}$ transmitted to the bandle. Two of these irons are required, heated over a largespirit lamp, and used alternately. A thick indiarubber tube, with a third of an inch calibre, seven inches in length, is passed up the bowel for about five inches. Strips of oiled lint are then arranged round the interior of the bowel extending as high as possible. Cotton wool thoroughly well dusted with iodoform is then evenly and carefully packed into the bowel between the tube in the centre and the oiled lint on the sides. Thi gives a firm, even support to the lower few inches of the bowel, while the escape of flatus \&c. is provided for by the tube. The support thus afforded at an early stage is, I consider, very material. The success of the operation depends on the care that is taken to prevent the descent of the bowel during the early stages of healing before the adhesions have become firm. After forty-eight hours the whole dressing is gently removed, the part thoroughly washed, and a clean dressing replaced. The desire to strain has generally passed off by this time, and it does not seem necessary to pass the dressing far up the bowel. After the first few days internal dressings can be dispensed with, but the tube, cleaned daily, is kept in for ten day s or more. It allows the easy passage of flatus without straining effort. By a small nightly dose of opium the bowels can be kept confined for ten days. Small doses of castor oil can then be given together with an enema if necessary. The patient must on no account sit up or strain, and the motion is to be passed lying on the side and the anus drawn a little from the middle line ; and this should be enforced for at least six weeks, whilst consolidation is taking place, otherwise the whole advantages of the operation may be lost. I think it is from want of attention to these details that failure may often be attributed. MIy experience of this operation coincides with that of Mr. Herbert Allingham, and I am thoroughly satisfied with the results in those cases which have come under my care, though on one occasion the cautery had to be repeated. The following case, for the notes of which I am indebted to my late house surgeon, Mr. C. H. Roberts, serves as an example of the operation and the benefit that may be expected.

"Mrs. P-, aged twenty-nine, was admitted into St. Bartholomew's Hospital, July 1st, 1889. The patient was a fairly healthy-looking woman, well nourished, bots bitterly complained of her trouble, and was in a very depressed condition on account of it. She has had difficulty wich her motions for eight years, being much troubled with constipation, at other times her motion coming away with a discharge streaked with blood. For the last four years the bowel has come down more or less on going to stool. This condition has gradually got worse, the quantity of bowel prolapsing increasing. At times constipation was very obstinate. She has little or no control over her motions. On rectal examination the prolapse was not down. The finger passed into a large cavity. There was absolute loss of all power in the sphincter. On asking the patient to strain, a large prolapse was apparent, the size of a foetal head. The neasurements were 6 in. in length, with a circumference of 9 in. The orifice at the summit of the prolapse pointed backwards. In front there was a large hernial pouch, containing small intestine, which could be reduced with a gurgling sound in to the abdominas cavity. There were two or three slight ulcerations in the mucous membrane, which was thickened and hypertrophied, and large hrmorrhoidal vessels traversed it. On pulling the prolapse with the fingers a further portion of the bowel could be brought down. In Jane, 1889, Mr. Harrison Cripps operated in the manner already described. Four lines were made by the actual cautery in the long axis of the gut, the large vessels having been previously ligatured; there was no baemorrage. The whole mass was then reduced, and strips of oiled lint placed in the bowel. A thick indiarubber tube was then passed into the rectum, and iodoform wool packed between it and the oiled lint. With the exception of some slight hæmorrhage and some rise of temperature, the protient did well. She had no pain, and the bowels were opened on the fourteenth day without any sign of the pro. lapse. After this the bowels were usually opened once a day after a small nightly dose of cascara sagrada. She was allowed to get np and walk about at the seventh week, and discharged on Sept. 2 nd.

August, 1890 : Examined to-day. The bowel feels quite healthy in every respect. She has to a great extent regained control over her motions, and has never had the least sign of prolapse since leaving the hospital a year ago.

\section{THREE CASES OF INFECTIVE PNEUMONIA OCCURRING IN ONE FAMILY.}

BY THOMAS OLIVER, M.A., M.D., F.R C.P., PHYSICIAN TO THE ROYAT INFIRMARY, NEWCASTLE-UPON-TYNE

Whether as the result of the wave of influenza whicl recently passed over this country, or of some other condition hitherto unrecognised, we have had during the summer months in Newcastle and the immediate district $a$ large number of cases of pneumonia, many of which have been so virulent and atypical that it is just a question how far the pneumonia has not been simply an incident in the morbid state.

On June 13th I was asked by Dr. Slater of Newcastle to see Mrs. D- , aged fifty-two, a strong, well-developed woman, who had been in excellent health until the week previously to that in which I saw her. Her husband had returned from Antwerp on May 29 th feeling very ill. At once he took to bed, and when seen on the following morning the case was regarded as one of pneumonia. This 